LA-UR. $95-2637$

LAUR-95-263\%

Title:

The Two Polymorphs of N-DNAT, A High Nitrogen Molecule

Author(s):

Kien-Yin Lee, $\mathrm{DX}-16$

Submitted to:

American Defense Preparedness Association,

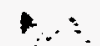

The International Symposium Energetic Materials Technology Sept. 24-27, 1995, Phoenix, AZ

DISTRIBUTION OF THIS DOCUMENT IS UNLIMITED
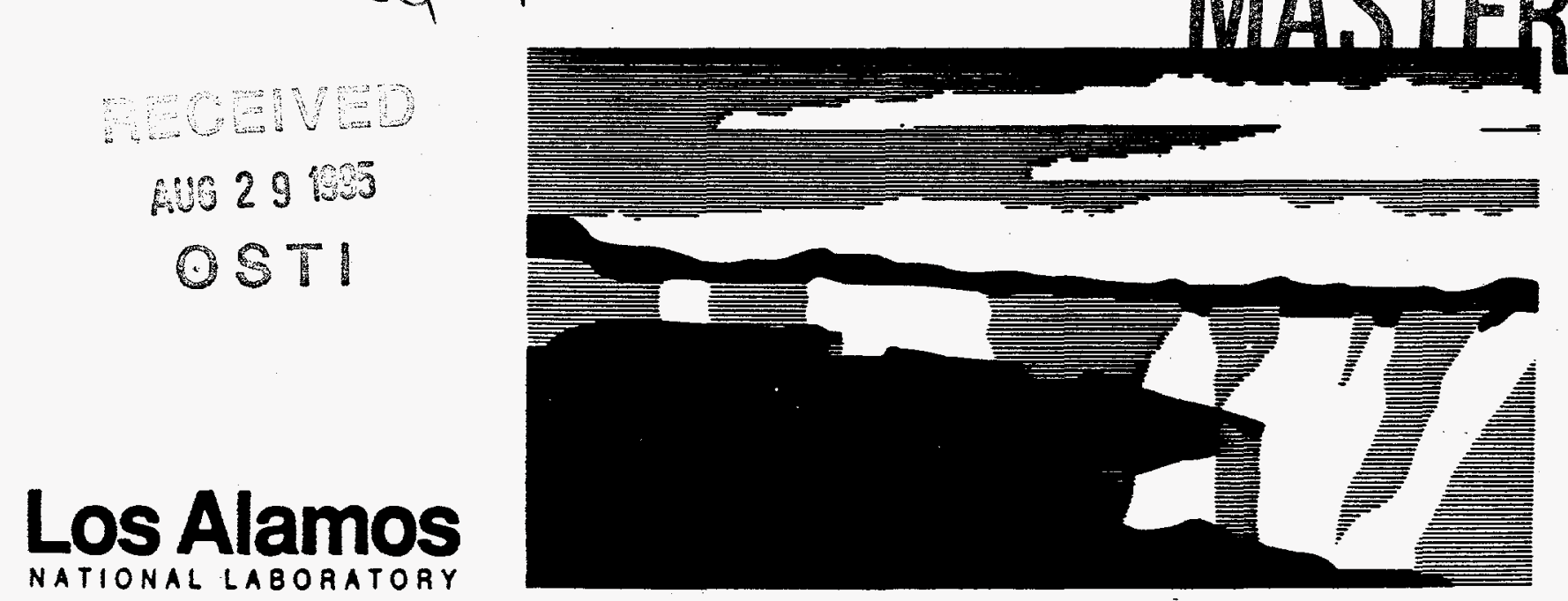

Los Alamos National Laboratory, an affirmative action'equal opportunity empidyer, is operated by the University of Celitemte for the U.S. Department of Energy under contrace W.7405-ENG-38. By acceptance of this atict, the publianer recognized that the U.S. Govemment reteine a nonexcheive, royalty-free license to publish or reproduce the puolished form of this contribution. $\alpha$ to allow others to do so. for U.S. Govemmem purposea. The Loe Alamos National Laboratory

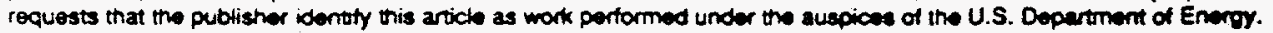




\section{DISCLAIMER}

Portions of this document may be illegible in electronic image products. Images are produced from the best available original document. 


\title{
The Two Polymorphs of N-DNAT, A High Nitrogen Molecule
}

\author{
Kien-Yin Lee \\ MS C920, Group HE Science \& Technology \\ P. O. Box 1663 \\ Los Alamos National Laboratory \\ Los Alamos, New Mexico 87545 \\ Tel: (505) 667-7131 E-mail: kyLee@lanl.gov \\ May Chan \\ NAWC, Code 474310D \\ China Lake, CA. 93555
}

\begin{abstract}
A novel azo triazole molecule was prepared. Based on X-ray crystallography data, this molecule, 1,1'-dinitro-3,3'-azo-1,2,4-triazole (NDNAT) exists in two forms. The yellow color polymorph has a crystal density of $1.701 \mathrm{~g} / \mathrm{cm}^{3}$, while the density of the orange crystal is $1.831 \mathrm{~g} / \mathrm{cm}^{3}$. Data from specific impulse (Isp) calculation indicates that N-DNAT is a potential candidate for propellant applications.
\end{abstract}

\section{Background}

For more than four decades, Los Alamos has pursued an active program in the synthesis and development of new high explosives to meet the changing requirements of explosives. For example, TATB, the thermally stable molecule that was employed in nuclear weapons, was developed when the requirement for an insensitive high explosive (IHE) was implemented during the early 60 's. ${ }^{(1)}$ In an attempt to meet the demand for an improved gun-propellant formulations, numerous new salts of NTO molecules were synthesized in the mid $80^{\prime} \mathrm{s}$, and were evaluated to be the ingredient replacing TAGN. ${ }^{(2)}$

Recently, the emphasis on transportation safety has led the demand for a new class of energetic materials. Currently, sodium azide $\left(\mathrm{NaN}_{3}\right)$ is the gas generant for inflating automobile safety bags. However, the use of $\mathrm{NaN}_{3}$ has resulted in many harmful incidents in this country. Hence, the search for a new, non-toxic molecule to replace $\mathrm{NaN}_{3}$ is an area of intense research in the automotive industry. The new class of high-nitrogen molecules is also demanded by the fire extinguishing community because of its flame extinguishment properties. At present, halogenated extinguishing agents 
(generally known as halon) are widely used in fire extinguishers for the protection of electrical and electronic equipment, petroleum production facilities and engine compartments, etc. However, halogens such as chlorine and flourine are suspected to be the elements responsible for the ozone depletion phenomenon in the ozonosphere. Therefore, research projects toward the search of flame extinghishment to replace halons are underway. The replacement candidate molecule requires a composition with a high content of nitrogen, yet with low total hydrogen.

Data from calculated burn performance of high-nitrogen content triazolone salts and other nitroheterocyclic energetic materials indicate that the flame temperatures of those molecules are low, and they produce low-molecular-weight gases as the burn products. $^{(3)}$ We are interested in azo triazoles because both 1,1'-dinitro-3,3'-azo-1,2,4triazole (N-DNAT) and its isomer, 5,5'-dinitro-3,3'-azo-1,2,4-triazole (DNAT) are highdensity molecules and are calculated to have a positive heats of formation (94.4 $\mathrm{kcal} / \mathrm{mol}$ ), as well as being a high-nitrogen molecule. ${ }^{(4)}$ Of particular interest is that $\mathrm{N}$ DNAT exists in two crystal forms with different color appearance and crystal densities. ${ }^{(5)}$ It appears that one can customize the molecule with the desired density for a specific application in mind. It is also our interest to find out if one polymorph is more sensitive than the other because of their different crystal color.

In this paper, the synthesis approach of both polymorphs of N-DNAT will be described, together with their explosive properties determined by preliminary sensitivity tests. Data from both BKW and specific impulse calculations of N-DNAT will also be reported.

\section{Experimental}

The synthesis of N-DNAT was carried out by nitration of 3,3'-azo-1,2,4-triazole (ATA) with acetyl nitrate at $0-6^{\circ} \mathrm{C}$, followed by precipitation from ice water. ${ }^{(4,6)}$

\section{Preparation of Orange N-DNAT (N-DNATOR)}

N-DNATOR was obtained by recrystallizing N-DNAT from acetone in the presence of a small amount of ethanol. The pale orange crystals were collected by filtration after leaving at ambient temperature for several hours.

\section{Preparation of Yellow N-DNAT (N-DNATYE)}

N-DNATYE was obtained by dissolving N-DNAT in a small amount of acetone, followed by the addition of ethanol until precipitate appeared. The suspension was then set aside at ambient temperature for 24 hrs. Pale yellow crystals were collected by filtration. 


\section{Preliminary Sensitivity Tests}

Samples of N-DNAT polymorphs were subjected for both impact and thermal sensitivity tests. The impact sensitivity test was done on a ERL-type machine equipped with type-12 tools and a microphone for sound analysis. A total of five shots were conducted. The thermal sensitivity was measured on a mg of sample by differential thernal analysis (DTA), which indicated a temperature imbalance between the sample and an inert.

\section{Results and Discussion}

The two polymorphs of a high-nitrogen azo triazole have been prepared. The molecule is symmetrical and has a nitro group attached to the triazole ring nitrogen. A thermal ellipsoid drawing of N-DNAT calculated from the X-ray analysis is shown in Figure 1.

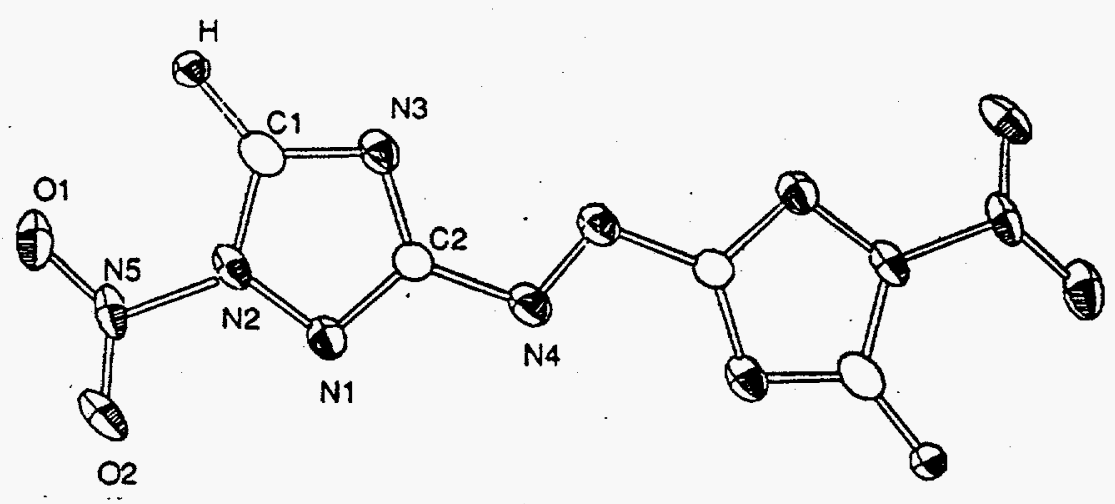

4

Fig. 1. A thermal ellipsoid drawing of N-DNAT

Both polymorphs are monoclinic and planar. However, the molecules in N-DNATOR form ribbons with the ribbons forming a herringbone pattern, while the molecues in $\mathrm{N}$ DNATYE are seen to alternate in orientation. ${ }^{(5)}$

To assure that the two polymorphs prepared are free from the other form, samples of both forms were analyzed by X-ray powder diffraction. Results from the diffraction patterns of both N-DNATYE and N-DNATOR forms confirm the purity of each sample, Figure 2 and 3. 


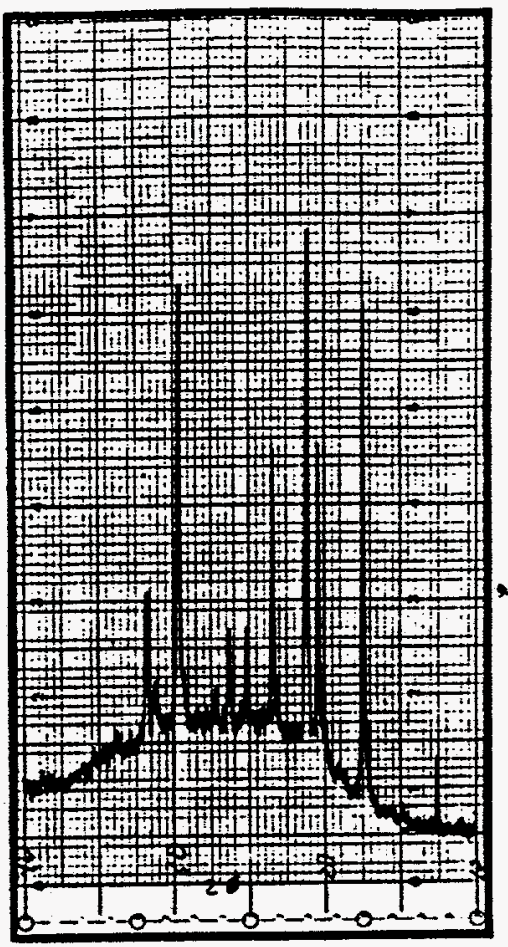

Fig. 2. X-ray powder pattern of N-DNATYE

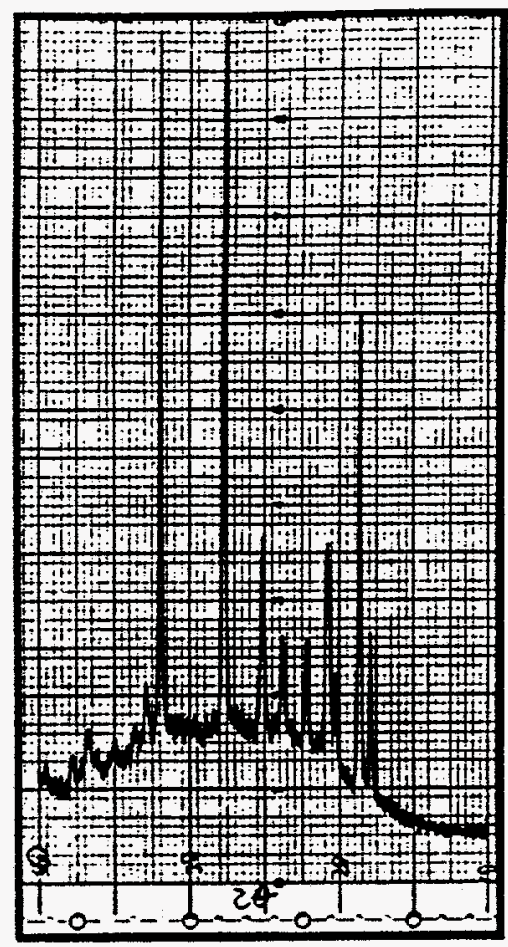

Fig. 3. X-ray powder pattern of N-DNATOR

Results from preliminary sensitivity tests on the two polymorphs indicate that $\mathrm{N}$ DNAT is a sensitive molecule, and the two forms gave similar response to impact. Table I summarizes the physical and explosive properties of N-DNAT. It can be seen that NDNAT has a DTA exotherm less than $200^{\circ} \mathrm{C}$. The herringbone molecular packing of $\mathrm{N}$ DNATOR seems to make this polymorph more stable than the other form. The DTA exotherm of N-DNATOR is about ten degree higher than that of the yellow form. Figure 4 is the DTA curve of N-DNATYE and the DTA curve of N-DNATOR is shown in Figure 5 .

Table I Physical \& Explosive Properties of N-DNAT

$\begin{array}{ll}\text { Molecular Formula } & \mathrm{C}_{4} \mathrm{H}_{2} \mathrm{~N}_{10} \mathrm{O}_{4} \\ \% \mathrm{~N} & 55 \\ \text { Density }\left(\mathrm{g} / \mathrm{cm}^{3}\right) & 1.831(\mathrm{~N}-\mathrm{DNATOR}) \\ & 1.701(\mathrm{~N}-\mathrm{DNATYE}) \\ \text { DTA Exotherm }\left({ }^{\circ} \mathrm{C}\right) & 147(\mathrm{~N}-\mathrm{DNATYE}) \\ & 157(\mathrm{~N}-\mathrm{DNATOR}) \\ \text { Impact Sensitivity }(\text { type } 12, \mathrm{~cm}) & \sim 11 . \\ \text { Heats of Formation }\left(\Delta \mathrm{H}_{\mathrm{f}}\right)(\mathrm{kcal} / \mathrm{mol}) & 94.4(\mathrm{calc} .)\end{array}$

Note that the percent nitrogen of N-DNAT is 55, which is very high compared to other common explosives, such as RDX ( $\% \mathrm{~N}$ is 38$)$ or NTO ( $\% \mathrm{~N}$ is 49$)$. Based on heats of 
formation of $94.4 \mathrm{kcal} / \mathrm{mol}$, and using RDX parameters, the BKW detonation velocity of N-DNATOR is calculated to be $8.191 \mathrm{~km} / \mathrm{sec}$, Table II. As shown in the Table, the C-J composition of the detonation products of N-DNAT mainly consists of nitrogen $\left(\mathrm{N}_{2}\right)$ and carbon dioxide $\left(\mathrm{CO}_{2}\right)$.

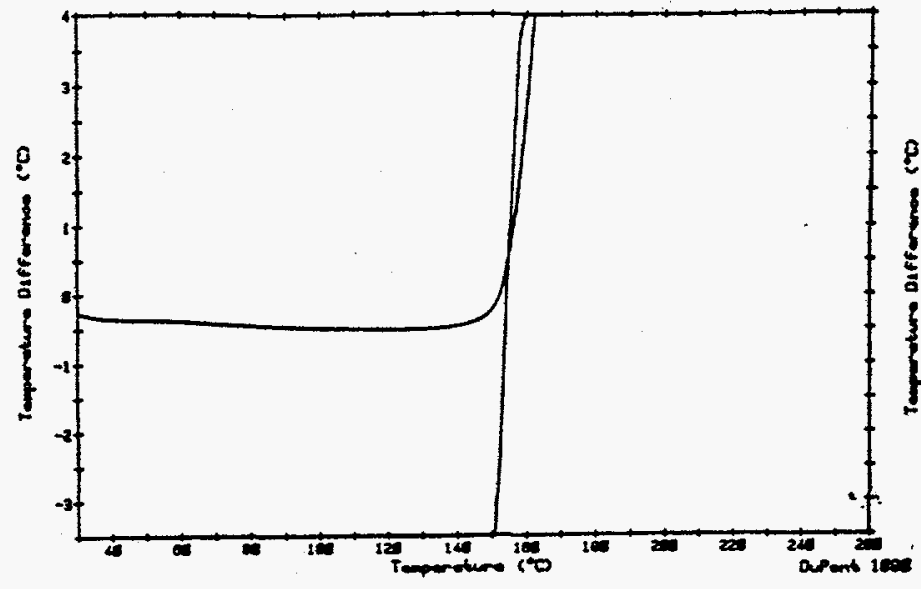

Fig. 4. DTA curve of N-DNATYE

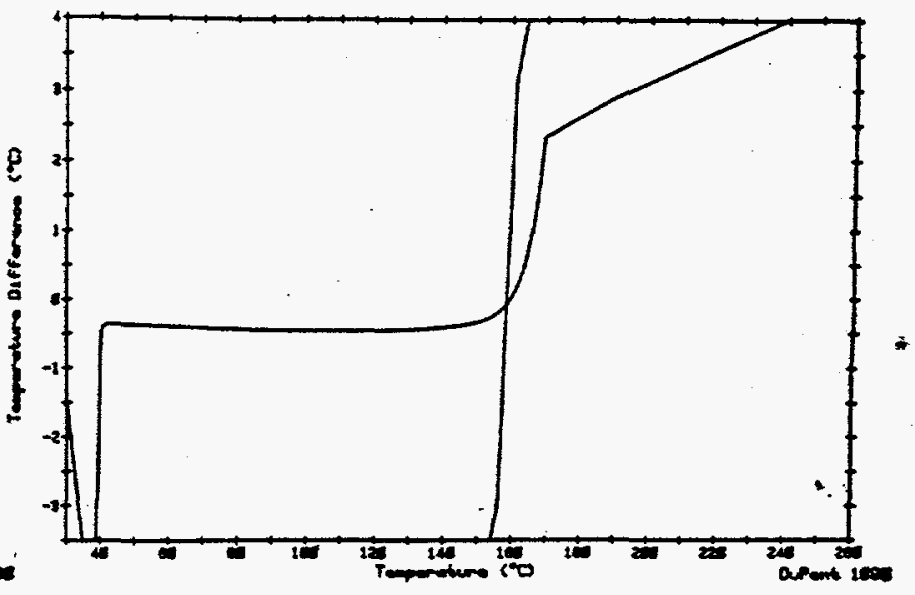

Fig. 5. DTA curve of N-DNATOR

Table II BKW Performance Calculation of N-DNAT

Molecular Weight

Pcj (kbar)

Dcj $(\mathrm{km} / \mathrm{sec})$

Gas produced (moles)

Detonation Gas Species (moles)

$\mathrm{H}_{2} \mathrm{O}(1.0)$

$\mathrm{O}_{2}(0.0)$

$\mathrm{CO}_{2}(1.498)$

$\mathrm{CO}^{2}(0.004)$

$\mathrm{N}_{2} \quad(5.0)$

Though N-DNAT is sensitive to impact, and is not suitable for explosives applications, the specific impulse (Isp) calculations of this molecule demonstrate the feasibility for propellant application. Table III is the Isp calculation of N-DNATOR. 
Table III Isp Calculation of N-DNATOR

$\begin{array}{ll}\text { Isp, sec(standard condition } 1000 \text { to } 14.7 \mathrm{psi}) & 225.3 \\ \text { D-Isp, sec } \mathrm{x} \mathrm{g} / \mathrm{cm}^{3} & 412.2\end{array}$

\section{Acknowledgment}

The authors are grateful to Dr. H. H. Cady for his X-ray powder diffraction pattern and DTA analysis.

\section{References}

1. Dobratz, B. M., "The Insensitive High Explosive Triaminotrinitrobenzene (TATB): Development and Characterization - 1887 to 1994, Los Alamos Report, 1995, in press.

2. Lee, K.-Y., and Stinecipher, M. M. "Synthesis and Initial characterization of Amine Salts of 3-Nitro-1,2,4-Triazol-5-one", Propellants, Explosives, Pyrotechnics 14, 241-244, 1989.

3. Stinecipher, M. M., Lee, K.-Y. and Hiskey, M .A. "New High-Nitrogen Energetic Materials for Gas Generators in Space Ordnance”, Proceedings of 31st AIAA/ASME/SAE/ASEE Joint Propulsion Conference, San Diego, CA. July 10-12, 1995.

4. Lee, K.-Y., "Synthesis of New Nitrotriazole Derivatives", Proceedings of the Working Group Meeting on High Energy Materials", Dec. 1984.

5. Cromer, D. T., Lee, K.-Y. and Ryan, R. R., "Structures of Two Polymorphs of 1,1'-Dinitro-3,3'-azo-1,2,4-triazole”, Acta Cryst. C44, 1673-1674, 1988.

6. Lee, K.-Y., "Preparation of 1,1'-Dinitro-3,3'-1,2,4-triazole", US patent 4,623, 409, Nov. 18, 1986.

\section{Glossary}

NTO -- 3-nitro-1,2,4-triazol-5-one

TAGN -- triaminoguanidine nitrate

RDX -- 1,3,5-trinitro-1,3,5-triazacyclohexane 